

\section{CHAND LC 4445 CAPITOL. EL TERCER VIAJE DE LE CORBUSIER A CHANDIGARH, MARZO-ABRIL 1952}

CHAND LC 4445 CAPITOL. THIRD TRIP OF LE CORBUSIER TO CHANDIGARH, MARCH-APRIL 1952

Pere Fuertes Pérez

RESUMEN El tercer viaje de Le Corbusier a Chandigarh, un año después de su primer contacto con la India, está íntimamente ligado a la definición del Capitolio en tanto que plataforma activa, capaz de poner en tensión los palacios institucionales de la que forman parte, y en tanto que realidad aislada de la ciudad y únicamente vinculada a la experiencia de las vastas dimensiones del país, al llano que la sustenta, a su techo de cielo y a las montañas que ponen fin al terreno horizontal. Durante los veinticinco días que permanece en el lugar, Le Corbusier define el Capitolio como recinto y determina sus límites, introduce la física de los reflejos combinados, intensifica la topografía como tema arquitectónico que anima la plataforma del Capitolio y dibuja los jardines que preceden al palacio del Gobernador, como síntesis de todos los temas expuestos. Los resultados darán lugar, a su vuelta, al plano con número de atelier CHAND LC 4445 CAPITOL. Más adelante, a medida que se definen los palacios, el Capitolio irá modificándose para alcanzar una nueva situación de equilibrio respecto a ellos, pero siempre en relación a aquello que sucedió durante esos días de 1952.

PALABRAS CLAVE Le Corbusier, Chandigarh, Capitolio, jardines.

SUMMARY The third trip of Le Corbusier to Chandigarh, a year after his first contact with India, is closely bound to the definition of the Capitol as an active platform, capable of pulling together the institutional palaces of which it forms a part and as a reality isolated from the city and uniquely linked to the experience of the vast dimensions of the country, to the plain that supports it, to its ceiling of sky and to the mountains that end the horizontal land. During the twenty-five days he stayed there, Le Corbusier defined the Capitol as an area and determined its limits. He introduced the physics of the combined reflections, intensified the topography as an architectural theme that animates the platform of the Capitol and drew the gardens that lead to the Governor's palace, as a synthesis of all the presented themes. The results would give rise, on his return, to the plan with the studio number of CHAND LC 4445 CAPITOL. Later, as the palaces came to be defined, the Capitol would be modified to achieve a new position of balance with respect to them, but always in relation to what happened during those days of 1952.

KEY WORDS Le Corbusier, Chandigarh, Capitol, gardens.

Persona de contacto / Corresponding author: pfuertes@coac.net Escola Tècnica Superior d'Arquitectura del Vallès. Universitat Politècnica de Catalunya 
$\mathrm{L}$ e Corbusier llega a Chandigarh, procedente de Ahmadabad, hacia el día 21 de marzo de $1952^{1}$ y permanecerá en el terreno hasta mediados del mes siguiente. La ciudad ya está en obras y los trabajos de construcción del palacio de justicia se iniciarán en pocos meses, bajo la dirección de su primo y antiguo socio Pierre Jeanneret. El primer ministro Jawaharlal Nehru se desplaza hasta allí, el día 2 de abril, para respaldar públicamente el proyecto de la nueva capital del Punjab Oriental, que el joven Gobierno ha considerado necesario tras la cruenta segregación entre Pakistán y la India en $1947^{2}$. En Ahmadabad todo avanza más lentamente. Los encargos recibidos un año atrás de diversos miembros de la Asociación de Hilanderos siguen todavía en discusión. No será hasta 1953 que dé comienzo la primera obra, la sede de la propia asociación.

Se trata del tercer viaje que Le Corbusier realiza a la India desde febrero de 1951. Durante los próximos 14 años, su rutina de trabajo incluirá, sin apenas variación, dos viajes anuales de un mes de duración, hasta sumar un total de 23. En esos momentos, sin embargo, poco puede imaginarse que Chandigarh le acompañará el resto de su vida.

Viajar ha sido y es una actividad esencial para Le Corbusier. Desde 1907 hasta 1911, su formación como persona y como arquitecto está vinculada a un programa de itinerarios por Europa que concluye con un viaje a Oriente, hasta el lejano Estambul. Seis años más tarde, abandona la Suiza natal y se establece en París.
Todo lo aprehendido durante estos años, meticulosamente dibujado y descrito en sus cuadernos de viaje y, sobre todo, impreso profundamente en su mente, irá liberándose lenta y persistentemente durante toda su obra.

Tras la primera guerra mundial, a medida que su prestigio y su capacidad polémica van en aumento, es invitado como conferenciante en numerosos países y sus cuadernos le acompañan en todo momento. Son viajes de carácter muy distinto y, a pesar de ello, la capacidad de observación y de aprendizaje de Le Corbusier se refuerza con nuevos puntos de vista, como el que ofrece el avión, revelándose como un eficaz instrumento de comprensión de la realidad a escala territorial. En esa escala se mueven sus propuestas urbanas, capaces de poner en relación la ciudad con la geografía, como sucede de manera visible con Río de Janeiro o Argel.

Pero ninguno de los planes que se sucederán durante esos años irá más allá de unos dibujos sobre el papel, y eso permite entender la negativa inicial a aceptar el encargo que le ofrece en 1950 una comisión facultada por el Gobierno de la India. Quizá, en ese instante, sopesa los esfuerzos volcados en los anteriores 19 planes urbanos y diversos estudios que no prosperaron. La mediación de Claudius Petit -Ministro de la Reconstrucción francesa y alma política de la unité en construcción-y del arquitecto británico Maxwell Fry serán decisivas para que cambie de opinión y vea en Chandigarh la oportunidad que ha estado esperando todos esos años. Le Corbusier cuenta con 63 años. 
A partir de este momento, cada viaje a la India será un concentrado de observaciones y decisiones, animadas por un objetivo. En unas semanas, deberá verter sobre el terreno su trabajo previo y reunir el material arquitectónico capaz de alimentar los siguientes seis meses. Los cuadernos de esos años constituyen un material muy valioso para reconstruir ese doble proceso y poder vislumbrar así las intenciones que subyacen en su arquitectura.

El primer viaje, realizado entre febrero y marzo de 1951, le permite trazar la ordenación urbana de la ciudad ${ }^{3}$ y conocer diversos ejemplos de arquitectura en Delhi y Ahmadabad, incluidas las operaciones de Edwin Lutyens en Nueva Delhi, que han concluido tan solo veinte años antes.

En este tercer viaje, Le Corbusier se concentra en el recinto del Capitolio. Con el proyecto para el palacio de Justicia terminado unas semanas antes y el Secretariado en fase avanzada, resulta urgente definir el soporte que los pone en relación entre sí y con el resto de edificios institucionales y que acabará dando lugar al plano CHAND LC 4445, de 5 de junio.

\section{HUELLAS SOBRE LA LLANURA}

El Capitolio se ha propuesto desde un inicio como periferia de la ciudad. Se podría pensar, por el parentesco con la ville Radieuse, que se encuentra a la cabeza de Chandigarh, dirigiendo su destino. Sin embargo, la ciudad se organiza en torno a un centro comercial y de servicios, ubicado en el Sector 17. Le Corbusier ha dispuesto el Capitolio deliberadamente al margen del funcionamiento cotidiano de Chandigarh; en una posición que sólo se explica por la proximidad de las cercanas montañas del Himalaya. A pesar de las diferencias, se puede reconocer la huella todavía fresca del centro cívico de Saint-Dié (1945), tomando como equivalentes el curso del río en ésta última y el canal artificial que debía separar el Capitolio de la ciudad.

En Saint-Dié, el centro cívico es una plataforma peatonal que aglutina las instituciones y los edificios culturales y que se prolonga, elevada sobre las vías de circulación, hasta cruzar el río. Como el Capitolio, se asienta en el llano y tiene por fondo la montaña. Incluso el Secretariado ocupará una posición y formato equivalentes a una de las dos unités que Le Corbusier ha previsto a ambos lados del centro cívico, favoreciendo la dirección río-montaña. Pero en Chandigarh no se levanta un ágora sino un extenso parque.

Las condiciones cambian y, si Saint-Dié se levanta sobre sus propias ruinas, la India permite a Le Corbusier enfrentarse a un terreno virgen, en el punto justo en el que la llanura inconmensurable sirve de soporte a los primeros Himalayas. Las dimensiones y el carácter cambian y, con ellos, las proporciones también lo hacen. Parece que las vastas dimensiones de la India tengan cabida en la composición, de modo que la arquitectura y la naturaleza resulten mutuamente reforzadas.

Si el Capitolio se constituye como parque, resulta tentadora la idea de que Le Corbusier considerase el arquetipo del chahar-bagh ${ }^{4}$, un jardín cuatripartito de origen persa en el cual el agua subraya cada acontecimiento geométrico y que los emperadores mogoles utilizaron con profusión en la India entre mediados del siglo XVI y finales del XVII. Los croquis esbozados durante el primer viaje parecen apuntar en esa dirección: un cuadrado de 800 metros de lado centrado en la Asamblea, yuxtapuesto a otro de 400 metros que rodea al palacio de Justicia; ambos divididos en cuatro partes. Sin embargo, esa combinación es extraña en estos jardines. Es más probable que el punto de partida sea un modelo concreto; y ese modelo se encuentra a escasos 22 kilómetros de distancia, en ruta hacia Simla, donde Le Corbusier está trabajando en el plan Director. De la visita a Pinjore, durante su primer viaje, quedan al menos tres testimonios: un esquema acotado de la planta y dos croquis desde el eje del canal central; el segundo, con fondo de montañas, tras las cuales se ubicará precisamente el Capitolio ${ }^{5}$.

El jardín de Pinjore, iniciado por el emperador Aurangzeb (1618-1707), responde a esa misma geometría de cuadrado y cuadrado doble, subdivididos en cuartos e hilvanados por un canal escalonado que salva el desnivel del terreno. Si bien el esquema inicial pronto se impregna de la mano de Le Corbusier, el Capitolio conservará hasta el final las improntas de ambas figuras hechas visibles, a partir del plano de 5 de junio, por la implantación de obeliscos en sus vértices. En Pinjore la geometría pretende resolver, a favor de la acción humana, la pugna entre arquitectura y naturaleza, domesticando a ésta última. En Chandigarh, Le Corbusier no lo plantea 


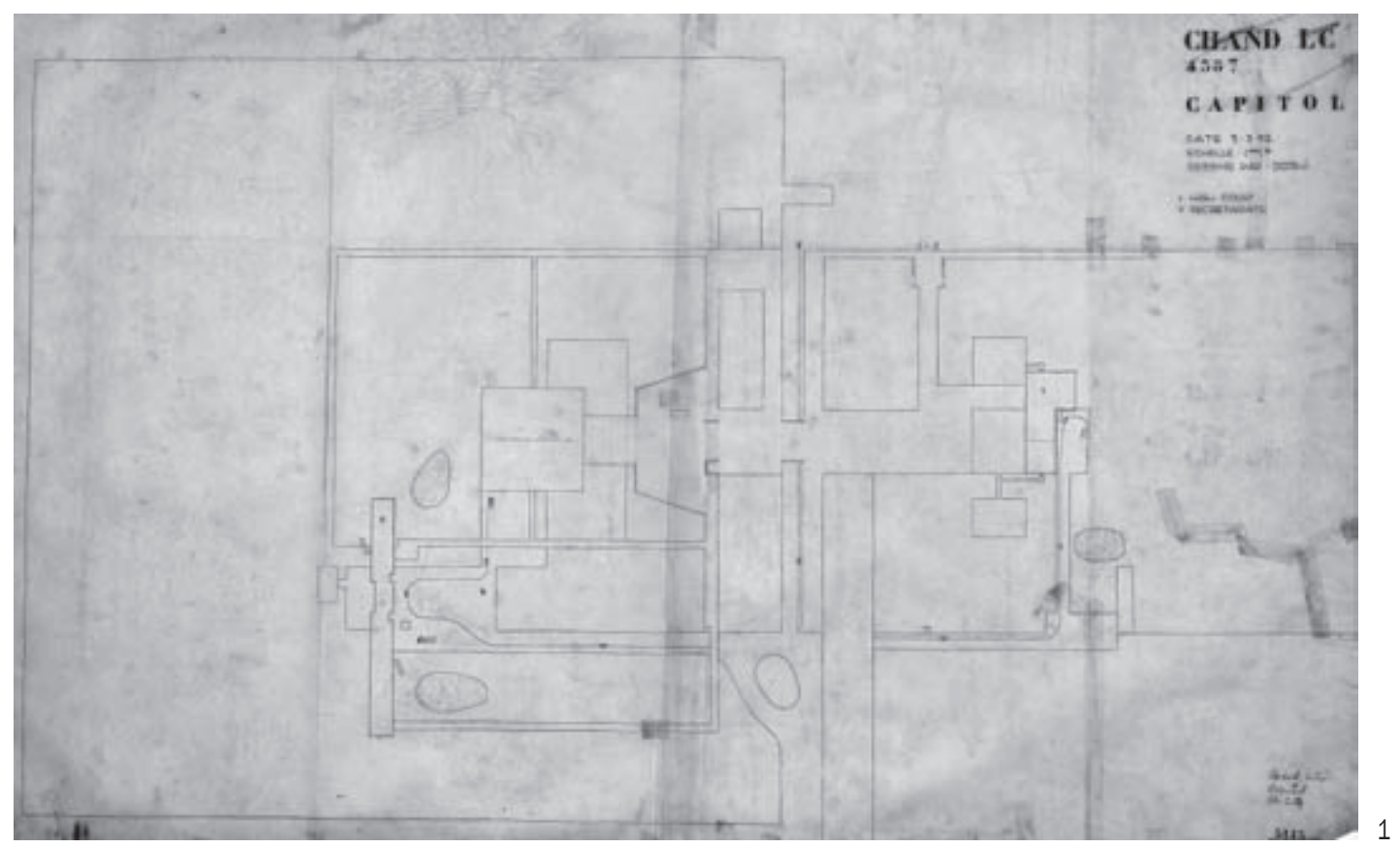

así. Incluso los grupos de mangos que salpican el Capitolio actúan como indicios de una naturaleza transformada por la presencia de la arquitectura, pero no sometida.

Dentro de la red que se va tejiendo en el Capitolio, los edificios se modifican y evolucionan. A cada movimiento de sus piezas, el conjunto se reequilibra. La jugada clave que tiene la propiedad de asentar al resto es la metamorfosis del Secretariado durante el segundo viaje de Le Corbusier 6 . Abandona la forma de pantalla vertical paralela a la montaña, desmontándose en dos mitades por su 'línea de corte', que se disponen una junto a la otra, separadas por la aparición de un cuerpo central de despachos ministeriales. El edificio se orienta perpendicularmente al Himalaya, girando $90^{\circ}$ respecto a su posición anterior. A partir de entonces, adopta la forma de límite oeste del Capitolio, de manera comparable a una de las dos unités que cierran los flancos del centro cívico de Saint-Dié.

\section{LAS REGLAS DE LA PARTIDA}

En el tercer viaje, Le Corbusier lleva consigo el plano CHAND LC $4387^{7}$ con la planta del Capitolio (figura 1). Con un contorno intenso y preciso, se dibujan los proyectos más avanzados: el palacio de Justicia y el Secretariado. Con trazo más leve, dos rectángulos indican la posición de la Asamblea y el palacio del Gobernador. La Mano Abierta ocupa su posición como contrapunto a la silueta de éste último. La situación de los edificios quedó fijada el noviembre anterior, in situ, con la ayuda de mástiles en las aristas de los palacios ${ }^{8}$. Tal como explicará

3. El plan director de Chandigarh quedará listo el 30 de marzo de 1951, firmado in situ por Le Corbusier, Albert Mayer -su antecesor como responsable del planeamiento-, Pierre Jeanneret y Maxwell Fry, ambos ‘senior architects' junto a Jane Drew, esposa de éste último.

4. Álvarez, Darío: "Ici pas d'autos = un parc. El Capitolio de Chandigarh, un jardín de la memoria”. Massilia 2004bis. Le Corbusier y el paisaje. Sant Cugat del Vallès (España): Associació d'idees, 2004. p. 101.

5. El dibujo en planta está fechado el 26 de febrero de 1951 (álbum Punjab, Simla, Chandigarh). Las vistas corresponden a los cuadernos de notas E18 (FLC W1-2-331, de 25 de febrero) y E19 (FLC W1-2-392, sin fecha). En el cuaderno E18, Le Corbusier anota "Patiala" en lugar de "Pinjore", quizás por el hecho de que los jardines pertenecieron al maharajá de esa ciudad.

6. FLC W1-2-27, "ne faut-il mettre le Secrétariat en travers?", octubre-noviembre 1951.

7. Se trata de un plano a escala 1:1000, de 5 marzo 1952, dibujado por B. Doshi (FLC 5145). Millet, Marion: Architecture: de la restitution face à l'inconstruit. París: École d'Architecture de Paris-Belleville, 2003. DEA no publicado. Millet cita por error el plano de atelier 4385.

8. "Au moyen de mats plantés sur le terrain, vérification et rectification de la situation définitive des édifices du Capitol (sic)". Grille Capitole, FLC P1-12-48, 18 noviembre 1951. La Grille Capitole es un documento elaborado al regreso del tercer viaje de Le Corbusier a París, con las decisiones estratégicas tomadas hasta el momento, indicando la fecha en cada ficha. 
más adelante en el Modulor $2^{9}$, fue necesario contrastar las proporciones y trazados de la planta con la realidad del lugar. Pero los edificios por sí mismos sólo constituyen una parte del Capitolio. Queda el espacio que los pone en relación y, a pesar de que el plano es parco en líneas, es la decantación de un proceso que contiene más información de la que aparentemente muestra.

El acto fundacional del Capitolio es un trazado de naturaleza matemática dibujado, en planta, sobre la llanura que sustenta la ciudad, en base a los cuadrados de 800 y 400 metros y sus descomposiciones. Este bastidor geométrico constituye un límite simbólico: segrega de la llanura ilimitada el espacio del Capitolio y, dentro de éste, traza el espacio vacío alrededor del palacio de Justicia y de la Asamblea, en base a un preciso juego de tangencias y axialidades en el que participan el palacio del Gobernador y el Secretariado. Da forma a un enrejado que permite regular la disposición de los edificios y la relación entre las partes.

A su vez, este enrejado sirve de soporte a un ámbito de naturaleza perceptiva, definido por la posición de los tres palacios y de la Mano Abierta y subrayado lateralmente por el muro del Secretariado. La densidad de acontecimientos sobre el plano hace reconocible este ámbito pero, sobre todo, lo define aquello que no se dibuja: la orientación coral que adoptan el pórtico del palacio de Justicia y de la Asamblea, junto con el perfil característico del palacio del Gobernador y de la Mano Abierta. Progresivamente, a partir de los primeros esquemas, esta explanada se perfila como una prolongación de los propios edificios sobre el suelo que, en el plano CHAND LC 4387, adopta la forma de estelas pavimentadas y estanques. El resto de los terrenos del Capitolio se limita a proveer espacio desocupado alrededor.

El palacio de Justicia y la Asamblea se disponen a caballo de dos cotas distintas: el nivel de la explanada central y el nivel deprimido por el que se mueven los vehículos, invisibles al paseante. Ambos edificios se atracan al borde de esa explanada, que adopta el aspecto de una plataforma doble, cortada a cuchillo por los pasos en trinchera. Con las modificaciones que se introducirán a raíz de este viaje, el palacio del Gobernador también adoptará esta eficaz estrategia de anclaje.
El proyecto del palacio de Justicia se ha terminado a inicios de marzo y ese desfase con el esquematismo del plano del Capitolio debe interpretarse con cautela, puesto que el edificio contiene las reglas básicas para su encaje: el pórtico que se abre a la explanada central, los estanques que lo preceden y el desnivel entre el acceso peatonal y el de vehículos. El pórtico permite establecer un vínculo con los otros edificios. Los estanques prolongan el palacio sobre el suelo, haciendo visible la impronta del espacio vacío que completa su volumen: "le cube d'aspect et le cube réel sont instantanément jaugés, pressentis par l'intelligence"10. El desnivel de una planta en su contacto con el suelo, asigna al palacio una posición respecto a la plataforma, anclado en su mismo borde. Las mismas reglas se observan para la Asamblea y, con excepciones, para el palacio del Gobernador, todavía simples rectángulos sobre el plano.

Si fuese necesario modificar la posición de un palacio, el pórtico, los estanques y el desnivel -y con éste, el límite de la plataforma- se desplazarían con el edificio. Este sistema abierto permite a Le Corbusier avanzar en la definición del Capitolio sin comprometer el proyecto ya terminado y le permitirá, en un futuro, modificar la Asamblea y el palacio del Gobernador, manteniendo la coherencia del conjunto.

El plano CHAND LC 4387 indica también la presencia de algunas colinas. La materia inerte de la llanura se transforma, desplazándose fruto de un impulso inicial, como ya indicó a propósito del plan Voisin para París de 1925: "Iorsqu'on creusera les gigantesques fondations des immeubles de bureaux, des montagnes de terreau surgiront de la fouille [...] nous laisserons s'accumuler les terreaux entre les fouilles, au beau milieu des parcs, nous planterons d'arbres ces montagnes, et les sèmerons de gazon"11. En marzo de 1952, los movimientos de tierras no se han iniciado todavía en el Capitolio, pero las colinas ya han hecho su aparición sobre el papel, ciñéndose al propósito pintoresco enunciado por Le Corbusier y, sin embargo, esto está a punto de cambiar.

\section{INTENSIFICACIÓN DE LA TOPOGRAFÍA}

En comparación con el plano CHAND LC 4445 de 5 de junio, publicado en la CEuvre complète 1946-52 (figura 2), el documento que lleva consigo a Chandigarh puede 


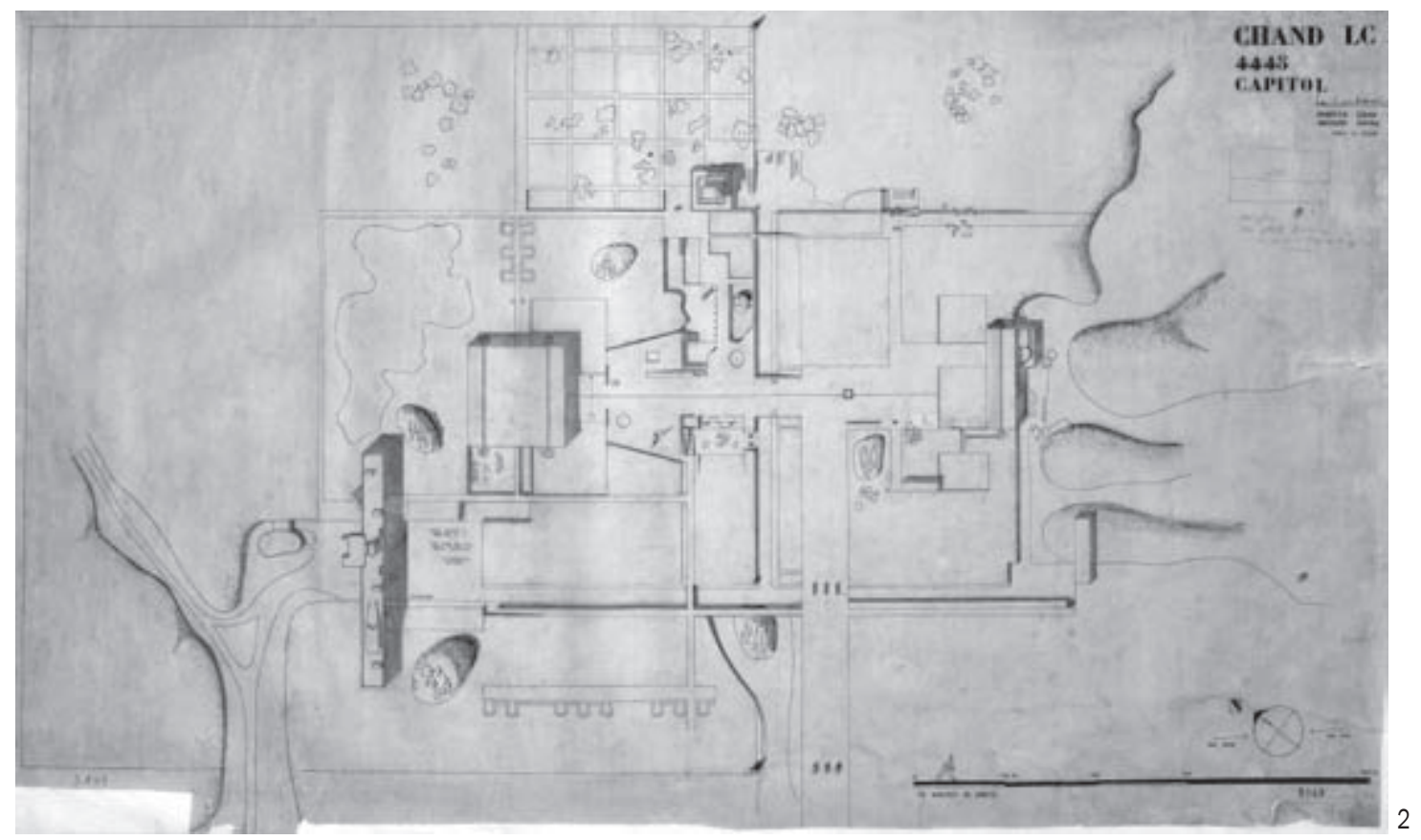

considerarse una simple base de trabajo, una planta preparada por el atelier para ser expuesta simultáneamente a las manos de Le Corbusier y a la acción de los elementos. Prueba de ello son los terrenos situados más allá de la explanada central -en el primer plano, una superficie neutra sin más información que los límites del Capitolio- que serán sometidos a la acción modeladora del agua que parece manar del Secretariado y del palacio de Justicia ${ }^{12}$; en este último, como antítesis de los estanques geométricos sobre los que desagua su cubierta.

Éste es un indicio de la naturaleza de los cambios que median entre ambos planos y que permiten avanzar que la topografía -en tanto que geometría y materia- y las propiedades del agua serán el tema arquitectónico del Capitolio que Le Corbusier active en este viaje. La abundancia de comentarios y croquis en este sentido así parece confirmarlo.

El día de su llegada a Chandigarh, se dirige al Capitolio; una llanura ocupada únicamente por los mástiles que han permanecido allí durante los últimos meses, señalando las aristas de los palacios. En tres páginas de su cuaderno dibuja esa llanura, a la que superpone los edificios, verificando el acierto de su posición; "sur place $=$ exact» escribe en dos de las páginas ${ }^{13}$. El único edificio que no dibuja es el palacio del Gobernador, del que más adelante dirá -refiriéndose a esos momentos- que "la distance qui sépare le Palais du Gouverneur de l'Esplanade principale du Capitol [sic] est si grande que l'on pouvait craindre un éloignement optique désastreux"14. El problema que se plantea no parece tener una solución

9. Le Corbusier: Modulor 2. Boulogne: L'Architecture d'Aujourd'hui, 1955. p. 227.

10. Le Corbusier: Vers une architecture. París: Crès, 1923. Reedición París: Arthaud, 1977. p. 154.

11. Le Corbusier: Précisions sur un état présent de l'architecture et de l'urbanisme. París: Crès, 1930. p. 197.

12. Le Corbusier dibuja una configuración idéntica en las inmediaciones del palacio del Gobernador que no llegará a plasmarse en el plano CHAND LC 4445. Croquis FLC W1-8-145, álbum Nivola I.

13. Croquis FLC W1-2-722, 723 y 726, carnet F24, fechados el 21 de marzo.

14. Le Corbusier: CEuvre complète 1946-52. W. Boesiger (Ed.). Zurich: Girsberger, 1953. Reedición Zurich: Artemis, 1957. pp. 142-143. 


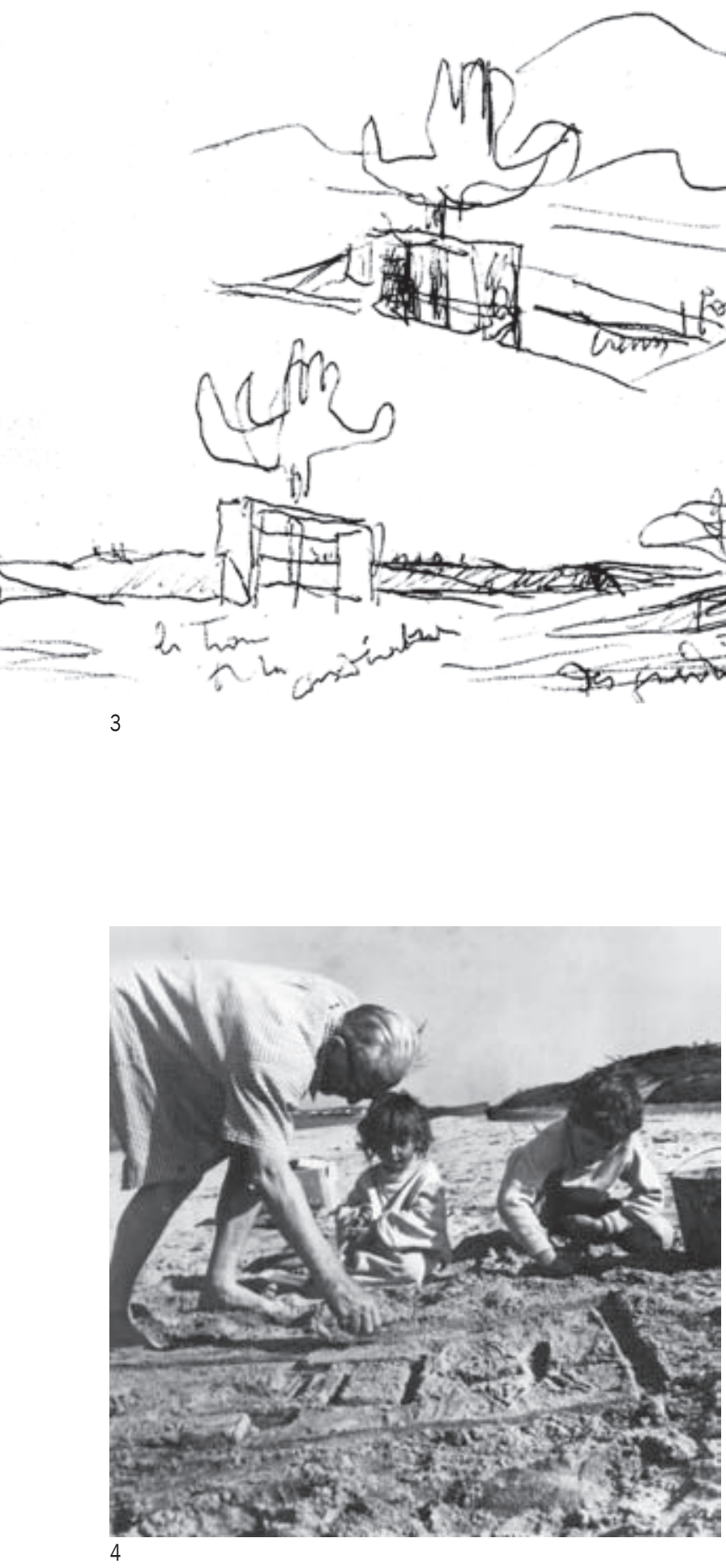

4
3. La mano abierta emergiendo de una "fossé de “Considération'. Croquis FLC W1-2-725.

4. Le Corbusier en Long Island, junto a los hijos de Nivola, el verano de 1951.

5. Dibujos del valle del M'zab en Argelia, que Le Corbusier visita en 1931, tal como aparecen en La ville radieuse. sencilla, sobre todo si, como parece, la posición del palacio no está en cuestión.

Volveremos más adelante sobre este asunto, pero detengámonos ahora en otro de los croquis de ese día (figura 3). Le Corbusier dibuja de nuevo la Mano Abierta, pero poniendo el acento en otro aspecto. El podio de la mano no se levanta del suelo sino que surge de un foso cortado en la arcilla, una "fosse de 'Considération' = agora en creux" o bien "le trou de la Considération"15. Le Corbusier aclarará que la mano "sort d'un vide, d'une fosse qu'il faut tailler dans l'argile de la plaine"16; una Ilanura materializada en arcilla que es necesario cortar.

Por su naturaleza material, es una operación comparable a la que realizó el verano anterior en la playa de Long Island ensayando la técnica de su amigo el escultor Costantino Nivola (Cerdeña, 1911 - Nueva York, 1988) ${ }^{17}$. Nivola moldea directamente la arena y luego vierte yeso o cemento líquido para obtener un calco perdurable. Más que esculturas en sentido estricto, se trata de relieves y contrarrelieves invertidos respecto al modelado original. En la imagen que se conserva (figura 4), Le Corbusier manipula la arena húmeda como la arcilla del llano, con el único matiz que, una vez obtenidas, las formas pueden invertirse mediante una sencilla operación. 


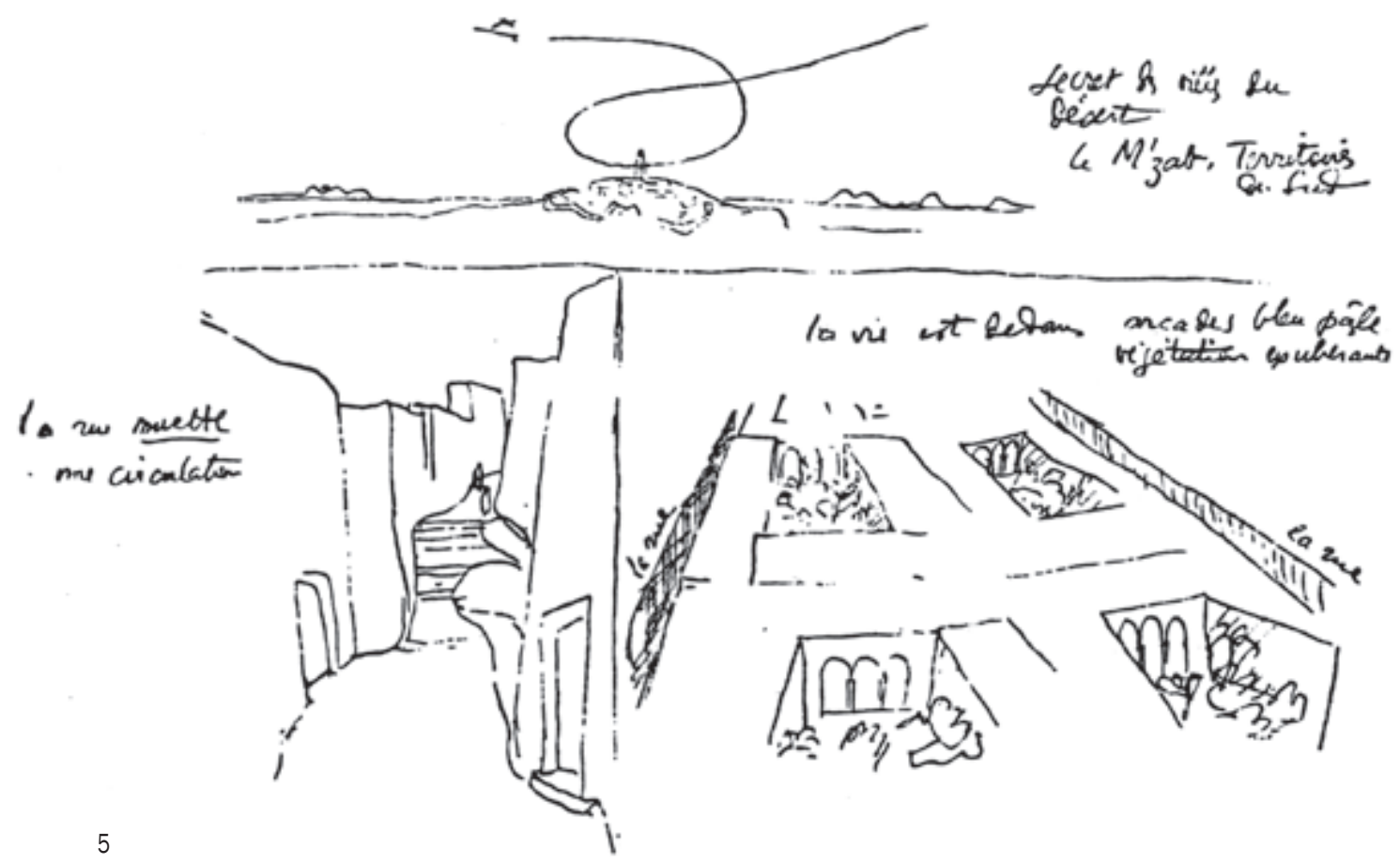

La imagen recuerda un comentario lejano, anotado en su viaje a Oriente de 1911, sobre Baja, un pequeño pueblo del inmenso llano húngaro construido con muros enlucidos en un amarillo intenso: "les rues appartiennent à la plaine, toutes droites, très larges, uniformes, coupées à angle droit [...] Ce sont, en quelque sorte, d'énormes coulisses puisque, partout, des murs hauts les ferment"18. La idea de hendiduras implica la existencia de una superficie continua virtual que ha sido cortada y esa imagen se reproduce, años después, en los dibujos de pueblos del M'zab argelino, cuando representa las calles y los patios como vaciados de aristas vivas en una superficie plana observada desde el aire (figura 5) ${ }^{19}$.

La existencia de hendiduras sobre el llano no es una novedad. Desde los primeros encajes del Capitolio, el paso de vehículos ha adoptado la forma de trincheras que dividen o delimitan la explanada: "le parc (comme la ville d'ailleurs) est taillé à vif dans une zone agricole, en toute liberté"20. Es un recurso ideado desde el exterior, desde arriba. En cambio, uno de los dos croquis de 1952 muestra el foso de la Mano Abierta desde dentro como ágora excavada, al abrigo de las dimensiones del Capitolio, como un lugar de reunión.

Entre el comentario sobre las calles de Baja y los croquis norteafricanos hay una variación substancial. El punto de vista se desplaza desde el interior de la incisión hasta un observatorio que permite ver los cortes desde lo alto. En el caso del Capitolio, parece darse el proceso inverso: las trincheras para vehículos son contempladas desde fuera por un observador a pie y, durante este tercer viaje, la vista y los pasos penetran en ese mundo rodeado de muros que nunca exponen su cara posterior.

15. Croquis FLC W1.2.725, carnet F24. La denominación "fosse de la considération" se empleará más adelante para referirse a un vaciado comprendido entre la torre de las Sombras y la colina geométrica, con la revisión de 1956 del Capitolio (CHAND LC 5340, FLC 5162), tal como se publica en Le Corbusier: CEuvre complète 1952-57. W. Boesiger (Ed.). Zurich : Girsberger, 1957.

16. Le Corbusier: Modulor 2. Boulogne: L’Architecture d'Aujourd'hui, 1955. p. 269.

17. "De passage à Long Island, en 1951, L-C fait une sculpture sur sable. Cette sculpture a été polychromée”. Le Corbusier: CEuvre complète 1946-52. W. Boesiger (Ed.). Zurich: Girsberger, 1953. Reedición Zurich: Artemis, 1957. p. 232.

18. Le Corbusier (Jeanneret, Charles-Édouard): Le voyage d’Orient. París: Forces Vives, 1965. Reedición Marsella: Parenthèses, 1987. p. 21.

19. Le Corbusier: La ville radieuse. Boulogne. L'Architecture d'Aujourd'hui, 1935. p. 231.

20. Le Corbusier: Modulor 2. Boulogne: L’Architecture d'Aujourd'hui, 1955. p. 225. 


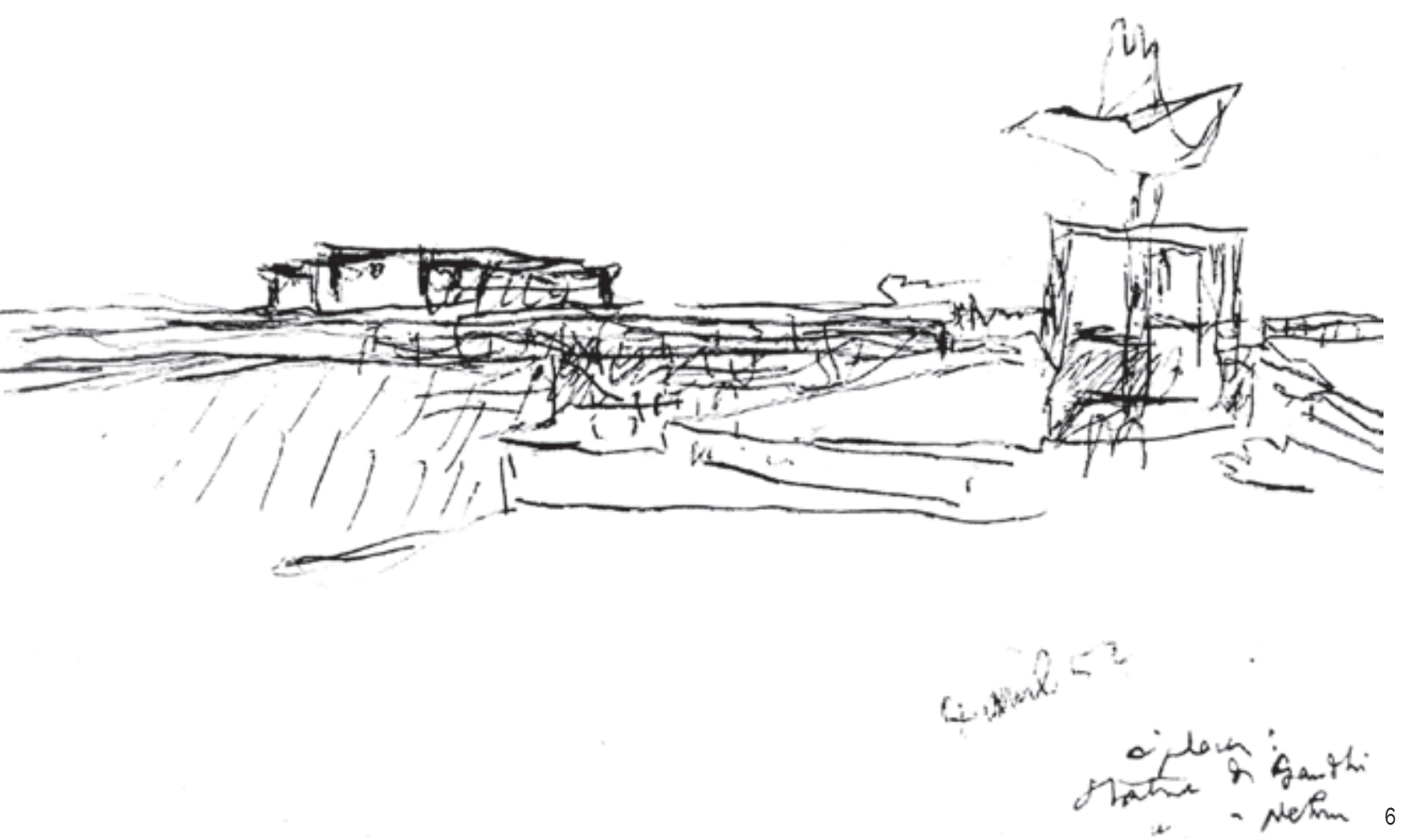

En un comentario algo posterior, Le Corbusier precisa que "si l'on descend (à piéton) on a de l'intimité au dessous du niveau de la plaine et c'est bon"21. La mano abierta emerge ahora de un foso que proporciona intimidad. Una intimidad comparable a la que ofrece el parapeto del ático de Beistégui, en pleno centro de París, al restringir los elementos que se muestran tras de sí: la torre Eiffel y el arco de Triunfo. Una intimidad controlada como la que proporciona la azotea de la unité de MarseIla, sobreelevando el muro perimetral hasta la altura de la vista y dejando asomar tan sólo las montañas lejanas. En el foso de la mano abierta, no son los monumentos de París ni las montañas marsellesas aquello que asoma, sino los palacios del Capitolio que han venido a ocupar su lugar, como muestran sendos croquis del 4 y 12 de abril22 (figura 6).
Para Le Corbusier, el llano sobre el que se asienta Chandigarh actúa simultáneamente a diversos niveles: es el terreno ideal que cede, sin ofrecer resistencia, a la implantación del trazado de la ciudad; es el contrapunto necesario de la montaña y es también la materia prima simbólica. La arcilla de la llanura sedimentaria es también materia modelable que dará forma al Capitolio a través de incisiones, vaciados y acumulaciones. Un breve comentario anotado en las páginas de su cuaderno, durante el primero de sus viajes a la India, da testimonio de esta relación material que Le Corbusier observa con el lugar: "1 village = le trou d'argile entouré d'arbres. II a servi à faire le village. II en est la mesure, le contenant"23. El vaciado en la arcilla da la medida de la aldea que se ha construido con ella; no pueden existir la una sin el otro. Son elementos 
complementarios que encajan; una interpretación del principio que Josep Quetglas denomina de simetría plástica ${ }^{24}$ y que nos devuelve a la cuestión de los movimientos de tierras.

Le Corbusier ya conoce los efectos que causa una elevación, por insignificante que parezca. En su segundo viaje anota: "il suffit d'une petite dune de $1 \mathrm{~m} 50$ pour annuler l'Himalaya" y deduce "1 petite dune fin ville début Capitol"25. Una duna puede eliminar la presencia de la ciudad, pero también puede servir de atalaya para contemplar el Capitolio: "trouver en certains points de la surface du Capitol, soit collines belvédères, soit terrassements dallés à 1 ou $2 \mathrm{~m}$ au dessus du sol" o bien "la dune de $2 \mathrm{~m}$ environ [...] donne déjà une vue panoramique"26. La intimidad del foso de la Mano Abierta se completa con estas observaciones, que atribuyen a cada estrato una cualidad distintiva, y dejan que la topografía actúe como principio activador: "1. être en contrebas, 2. monter le talus, 3. être à niveau de la plaine, 4. monter à $2 m$, à 4 , à $6^{\prime 27}$.

Los apuntes sobre elevaciones y excavaciones en el terreno introducen un cambio de perspectiva instantáneo. Ahora que resulta más necesario que nunca el conocimiento que brinda un ojo en movimiento, la activación de la topografía ofrece una alternativa a los largos recorridos como único modo de aprehender el Capitolio, o de sustraerse temporalmente de su presencia. Para ello, sólo es preciso introducir los movimientos en el eje vertical. Se está preparando, de esta manera, una parte de la solución al difícil problema de cómo vincular el palacio del Gobernador a la explanada central. Pero eso no sucederá hasta el día 11 de abril.

\section{LOS LÍMITES DEL CAPITOLIO}

Una de las cuestiones clave para comprender la actuación de Le Corbusier en el Capitolio que es la de su aislamiento; es decir, de su condición de recinto. Del apunte sobre la duna que anula el Himalaya puede establecerse un silogismo. Si la duna tiene esa propiedad, su colocación en el límite entre el Capitolio sólo puede tener un objetivo: anular la ciudad. Para establecer sus reglas, Le Corbusier necesita delimitar un tablero de juego; desvincularlo del exterior. Ya lo ha situado tangente al trazado urbano, en contacto con el llano desocupado que precede a las montañas. Ahora es necesario comprobar que "plus rien de la vie extérieure ne se manifestait ici; seuls présents, le Pentélique au loin, créancier de ces pierres, portant à son flanc la marmoréenne blessure et l'Hymette colorée de la plus opulente pourpre"28. El comentario hace referencia al recinto de la Acrópolis ateniense, que marcó su viaje de 1911 y cuyos efectos impregnan toda su obra, como sucede con la habitación a cielo abierto del ático de Beistégui o la azotea de la unité. Bastaría sustituir los montes Pentélico e Himeto por los Himalayas, acreedores del agua que alimenta la llanura, y la frase parecería escrita para la ocasión. Los límites del Capitolio deben ejercer de guardianes de la intimidad de un espacio exterior interiorizado, solo relacionado con el llano sobre el que se asienta modificándolo, el techo de cielo y las propias montañas.

En este tercer viaje, establecerá el siguiente "principe: il faut tirer une horizontale du mur [...] et qu'un ruban lumineux coupe net l'horizon, le mettant au plan extrême [...] À l'opposé (côté ville) c'est une futaie alignée et taillée de cyprès?"29. La pequeña duna deja paso a una arboleda

21. Croquis FLC W1-2-749, del carnet F24.

22. Croquis FLC W1-2-735, del carnet F24 y FLC 5862.

23. Croquis FLC W1-2-345, del carnet E18, febrero de 1951.

24. "La materia no se crea ni se destruye, sólo se traslada: primer principio de la simetría plástica. Cuanto falta de un lado aparece en el otro". Quetglas, Josep: "Viajes alrededor de mi alcoba". Artículos de ocasión. Barcelona: Gustavo Gili, 2004. p. 91.

25. Croquis FLC W1-2-638, carnet E23.

26. Croquis FLC W1-2-739 y 740 respectivamente, carnet F24.

27. Croquis FLC W1-2-744, carnet F24.

28. Le Corbusier (Jeanneret, Charles-Édouard): Le voyage d'Orient. París: Forces Vives, 1965. Reedición Marsella: Parenthèses, 1987. p. 159.

29. Croquis FLC W1-2-739, carnet F24. 
7. El límite nordeste del Capitolio y detalle de la mano abierta interrumpiendo un "mur spécial". Croquis FLC W1-8-132.

8. Los jardines del palacio del Gobernador sobre la explanada central, con la anotación "des pièces d'eau". Croquis FLC W12-740.
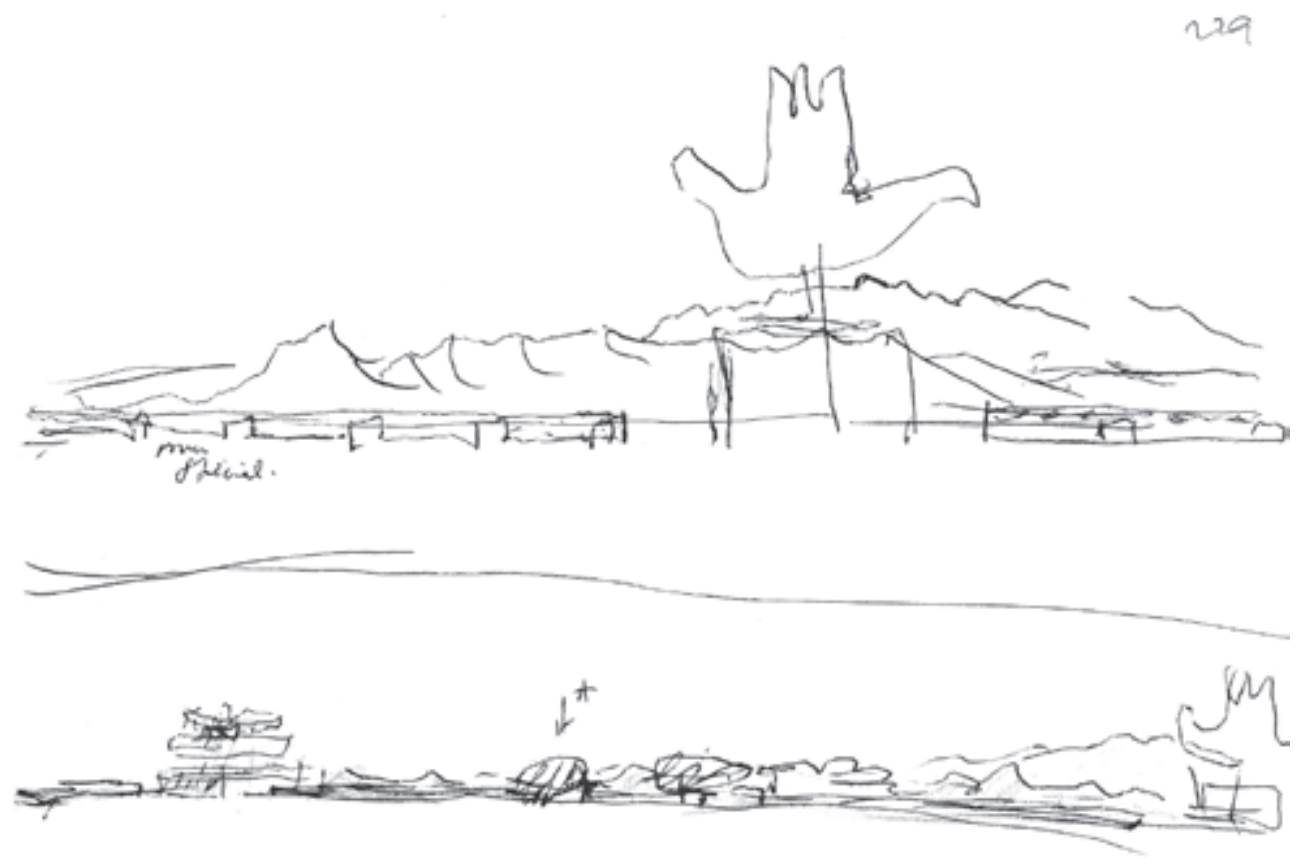

como muralla efectiva con la ciudad, mientras una cinta luminosa sirve de base a las montañas que se recortan tras ella. Le Corbusier dibuja ese muro de 1'40 metros en su cuaderno con la nota "mur spécial"30 (figura 7).

El carácter que adopta el Secretariado adquiere en este contexto todo su significado. Constituye una parte de los límites laterales del recinto, pero no todos. Consciente de ello, Le Corbusier dibuja una solución que incorpora de nuevo la vegetación, en forma de "chambres d'ombre noire" 31 , una secuencia de recintos que recuerdan los pliegues de un telón y que, en el plano de 5 de junio, adoptarán un trazado sinuoso continuo, como el de la arboleda que aísla el Capitolio de la ciudad.

Enelsiguienteviaje, ennoviembre de 1952, LeCorbusier se referirá al Capitolio como un "jardin de Vauban"32, el célebre ingeniero militar de Luis XIV que sistematizó el arte de las fortificaciones en Francia. En realidad, no existen jardines de Vauban, sino un modo de manipular la topografía para ocultar los puestos de defensa y ataque. Esta analogía sólo puede entenderse en relación a la necesidad de aislamiento; procurando una suerte de fortaleza Vauban invertida que no permite escapar a la mirada.
Este será el punto de partida para el uso de la topografía en la definición de los límites del Capitolio. Las modificaciones del terreno que introduce Vauban en Francia y Le Corbusier en Chandigarh pretenden pasar desapercibidas. A diferencia de la vegetación, no actúan como muros, sino como horizontes sobreelevados que convierten el recinto del Capitolio en una plataforma aparentemente abierta, pese a la eficacia de las defensas dispuestas en sus límites. Tal como los define, éstos son los elementos del Capitolio: "jardins, bassins, palais et horizons"33.

\section{REFLEJOS COMPUESTOS}

Recordemos la visita que Le Corbusier realiza al jardín de Pinjore durante su primer viaje. El jardín se adapta a un terreno en pendiente que desciende hacia las montañas, originando un canal en varios niveles, conectados entre sí por saltos de agua o por conducciones invisibles. Un mes después, asiste a una recepción en Nueva Delhi ofrecida en la antigua Viceroy's House de Lutyens, ahora palacio presidencial. De esa velada queda un comentario sobre el "jardin à la mongole [sic]. Le soleil se couche dans l'axe, partout reluisent l'eau, les 

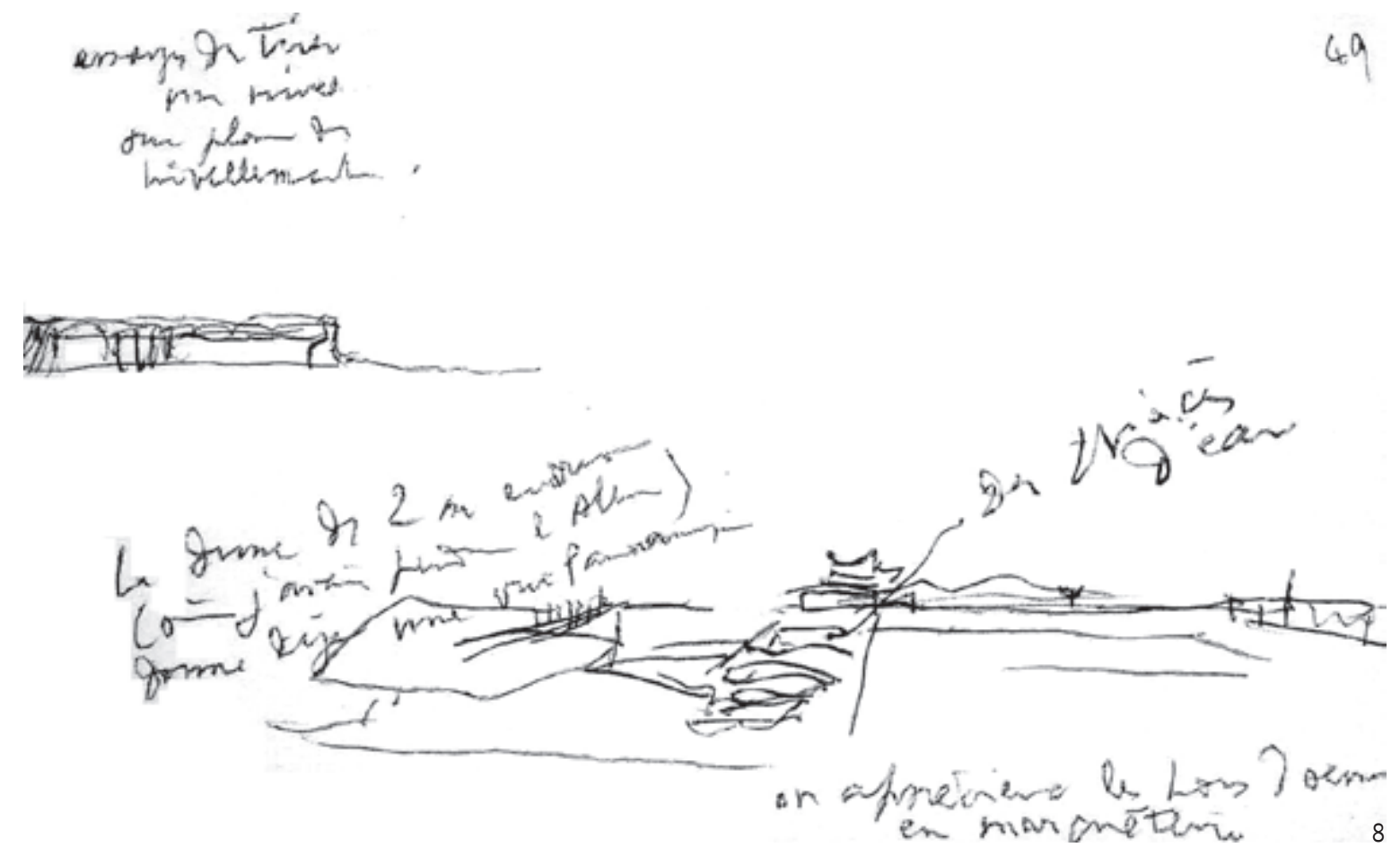

bassins et les chemins d'eau" ${ }^{44}$. En consonancia con esta presencia sugerente, el agua se manifiesta en el Capitolio asociada a los estanques reflectantes del palacio de Justicia y la Asamblea.

En el caso del palacio del Gobernador, un pequeño croquis inicial representaba la silueta del edificio ante las montañas precedido por un trazado geométrico con el que Le Corbusier pretende "étendre un tapis d'eau, rendre visible par des positions surélevés de face à celui" así como "créer un élément vertical"35 que ponga en relación el jardín de agua con el edificio y los Himalayas. El parecido con el croquis de los jardines en Nueva Delhi es razonable y eso supondría seguir los pasos del palacio de Justicia y de la Asamblea, aunque con un estanque de proporciones muy distintas, como el que dibuja ahora en su cuaderno junto a la anotación "des pièces d'eau", y el comentario "on appréciera le hors d'œuvre en marqueterie"36 (figura 8), en referencia a la posición elevada que ofrece una duna o la rampa que dibuja en la página opuesta, como primera versión del monumento a los Mártires de la división del Punjab.

En este tercer viaje se suceden comentarios en los que Le Corbusier se interesa más a fondo por la naturaleza de los reflejos: "ici un point $2 \mathrm{~m}$ en contrebas. Se reflètent les volumes ou surfaces verticales ou obliques qui sont à coté de l'eau. I/ faut créer des éléments de réflexion

30. Croquis FLC W1-8-132, álbum Nivola I.

31. Croquis FLC W1-2-748, carnet F24.

32. Croquis FLC W1-2-858, carnet F26.

33. Grille Capitole, FLC P1-12-48, ficha 123-1, 5 junio 1952.

34. Croquis FLC W1-2-399, carnet E18.

35. Publicado en Le Corbusier: CEuvre complète 1946-52. W. Boesiger (Ed.). Zurich: Girsberger, 1953. Reedición Zurich: Artemis, 1957. p. 143.

36. Croquis FLC W1-2-740, carnet F24. 
N3_VIAJES Y TRASLACIONES

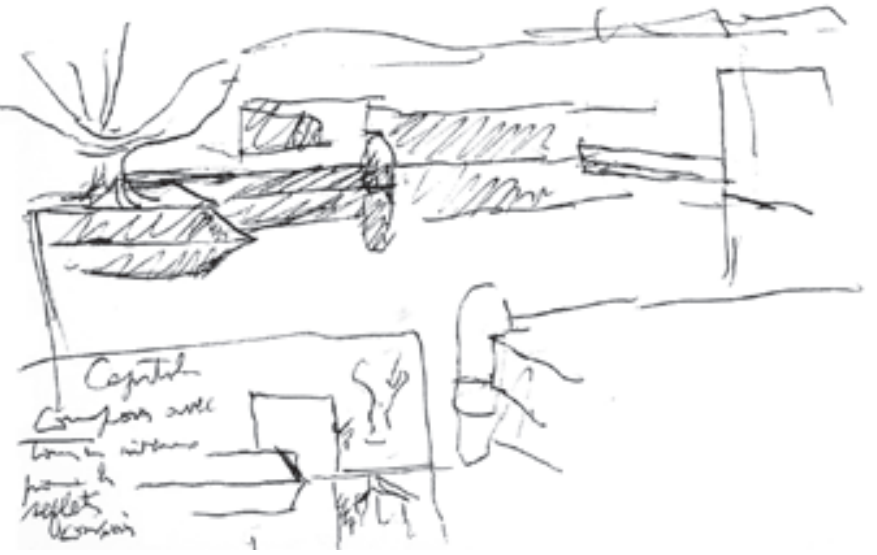

9
9. Le Corbusier se ejercita en la física de los reflejos compuestos. Croquis FLC W12-753.

10. Le Corbusier esboza unos jardines a la mogol ante el palacio del Gobernador. Croquis FLC W1-8-142.

11. Un molino de agua con la indicación "le jeu des reflets et des niveaux". Croquis FLC W1-2-756, de 11 abril 1952.
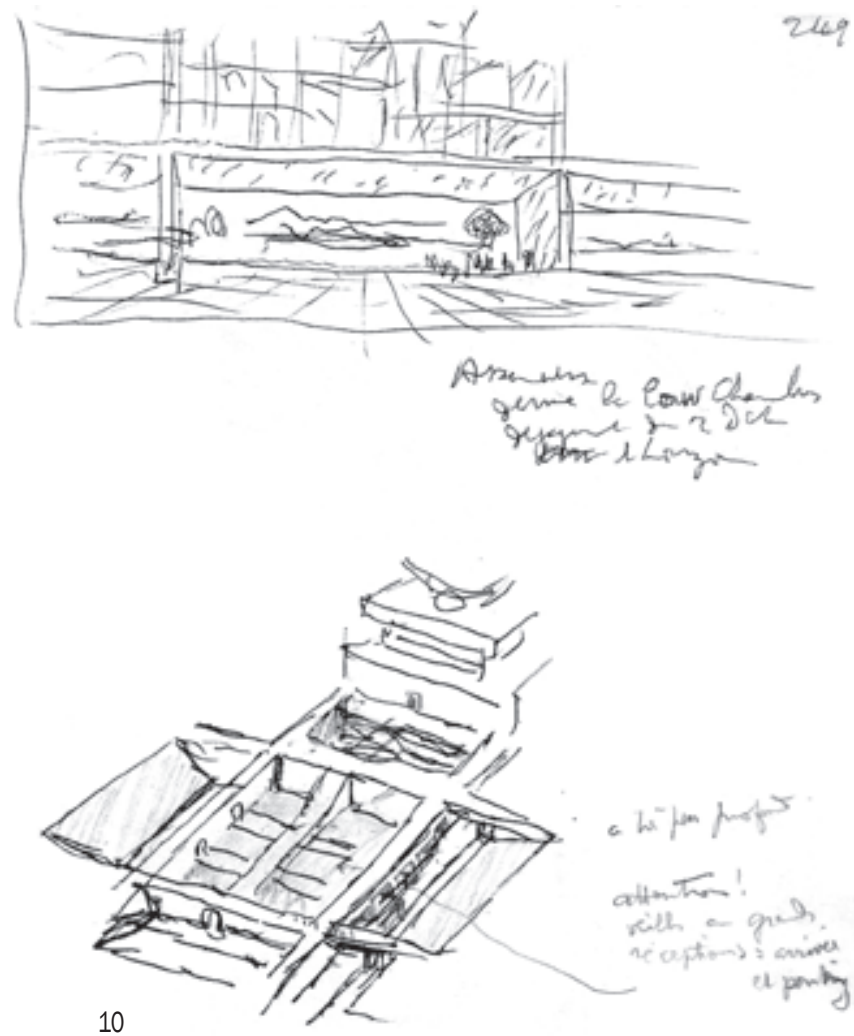

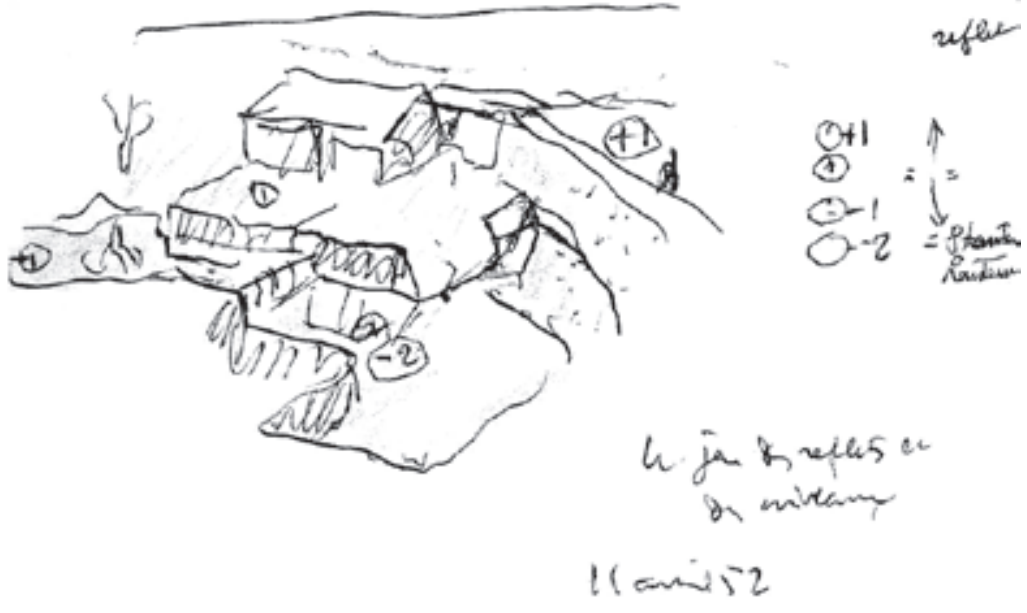

11 
sur épure exacte"37. Para determinar el efecto que producen, es necesario controlar los mecanismos de la reflexión para perfilar la arquitectura con trazados exactos. En pocos días concurren estos apuntes in situ con lo que, sin duda, son ejercicios de entrenamiento que muestran disposiciones de muros y otros elementos de alturas y formas variables, con sus reflejos invertidos sobre la superficie del agua: "composer avec tous les niveaux pour les reflets composés"38 (figura 9).

En esta observación se dan cita dos elementos que hasta ahora se habían manifestado por separado: los niveles que alteran la rasante de la explanada, confiriéndole ciertas cualidades, y los reflejos que provoca la superficie del agua, dando como resultado lo que Le Corbusier denomina 'reflejos compuestos'. Esta idea, que se ha ido perfilando en esos días, desencadenará la solución que adopte finalmente el palacio del Gobernador: "recherche sur les lieux de la physique des reflets dans l'eau pour favoriser l'apparition du Palais du Gouverneur" y "décision de créer un jeu de bassins à niveaux différenciés pour favoriser l'apparition du Palais du Gouverneur"39.

En un croquis sin fechar ${ }^{40}$, Le Corbusier dibuja el palacio precedido por un intrigante jardín a la mogol (figura 10). Se trata de una axonometría con un juego entre caminos a nivel de la plataforma, que se cruzan sobre un jardín deprimido, apto para "veilles en grands réceptions" en el que parecen alternarse estanques y otros caminos. La trinchera central del Capitolio, que conduce al palacio, ha pasado de ser un corte vertical del terreno a tener una sección asimétrica entre un muro de hormigón -el material que resuelve por igual edificios y accidentes topográficos- y un talud verde, que se conservará en el plano CHAND LC 4445. Esa misma sección, rotada hacia los otros lados, es la que devuelve el jardín deprimido a la rasante de la explanada, haciendo aparecer a los caminos como puentes. La propuesta se descarta pero, en cierto modo, la imagen de unos pasos elevados se mantiene en la solución final, gracias al efecto que producen los reflejos sobre las pasarelas que cruzan el agua o que la limitan del lado de la trinchera.

De hecho, no se trata exactamente de una propuesta descartada, sino desplazada unos metros en dirección sudeste, hasta cruzar el eje transversal del Capitolio. Con pocas transformaciones, Le Corbusier adaptará el jardín deprimido como acceso desde el vehículo en las grandes recepciones de la Asamblea, de manera análoga a lo previsto para el palacio del Gobernador. Será el germen del nuevo foso de la Consideración, definido en 1956 entre la presencia imponente de una colina geométrica y la torre de las Sombras. Con esta adaptación, hace gala de su capacidad para reaprovechar y transformar incesantemente sus propias creaciones.

En contraste con el orden cartesiano de esta solución, Le Corbusier escribe al pie de dos croquis distintos: "une composition extravagante d'eaux et des niveaux"41. Ya se refirió a su arquitectura como "pittoresque" en uno de los cuatro esquemas con los que resumía las investigaciones de la década de 1920 sobre la casa en la CEuvre complète ${ }^{42}$; de modo que "extravagante" no queda tan lejos de aquella expresión ni de alguna de sus composiciones pictóricas en las que se dan cita numerosos objetos de contornos complementarios que Ilenan, hasta saturar, la superficie del lienzo.

En este contexto, la visita a un molino de agua en las inmediaciones de Chandigarh le confirma la dirección correcta (figura 11). "En observant le jeu de reflets, très particulièrement dans un petit moulin de village, Le Corbusier se confirmait dans l'idée que l'emploi des bassins à différents niveaux peut assurer des rapprochements optiques précieux" 43 dirá, refiriéndose a él mismo en tercera persona. El croquis ofrece datos sobre la altura relativa de las diversas plataformas y caminos, a partir de la cual se modifica notablemente el reflejo en el curso de agua, dividido a su vez en dos niveles distintos ${ }^{44}$.

37. Croquis FLC W1-2-746, carnet F24.

38. Croquis FLC W1-2-753, carnet F24. También en FLC W1-8-145, álbum Nivola I.

39. Grille Capitol, FLC P1-12-48. Fichas II y III del palacio del Gobernador, fechadas respectivamente 11 abril 1952 y abril 1952.

40. Croquis FLC W1-8-142, álbum Nivola I.

41. Croquis FLC W1-2-755, carnet F24 y FLC W1-8-145, 11 abril 1952, álbum Nivola I.

42. Le Corbusier; Jeanneret, Pierre: CEuvre complète 1910-29. W. Boesiger(Ed.), O.Stonorov(Ed.).Zurich:Girsberger, 1929. ReediciónZurich:Artemis, 1964 . p. 189.

43. Le Corbusier: CEuvre complète 1946-52. W. Boesiger (Ed.). Zurich: Girsberger, 1953. Reedición Zurich: Artemis, 1957. pp. 142-143.

44. Croquis FLC W1-2-756, carnet F24. Publicado en Le Corbusier: CEuvre complète 1946-52. W. Boesiger (Ed.). Zurich: Girsberger, 1953. Reedición Zurich: Artemis, 1957. p. 142. 


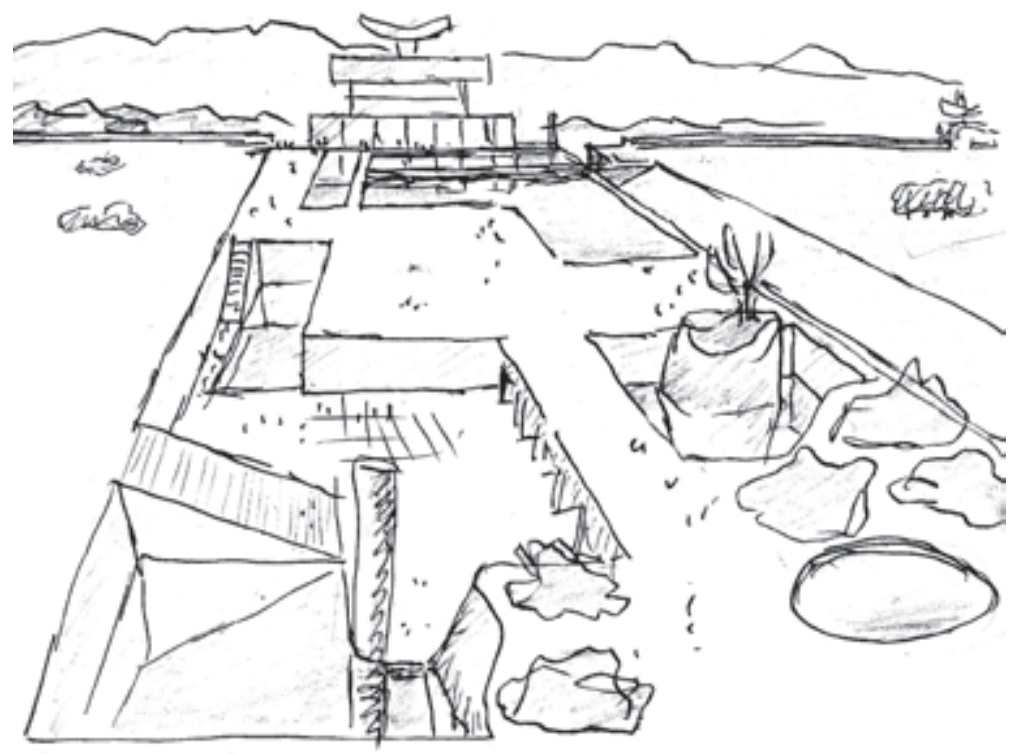

12. "Le dessin définitif du Palais du Gouverneur", tal como se publica en la CEuvre complète, de 12 abril 1952.
$12 \underset{52}{\operatorname{arnd}}(2)$

Si los reflejos deben asegurar la aproximación óptica del edificio, conviene evitar la disposición del palacio de Justicia y de la Asamblea, dado que el efecto de los estanques se pierde con la distancia. En cualquier caso, los fragmentos producidos por la disposición de estanques en diversos niveles tampoco desdobla nítidamente el edificio. Pero una observación atenta del molino de agua desvela que, en realidad, los estanques no se comportan de este modo. El acercamiento óptico al que hace referencia Le Corbusier no se articula mediante el desdoblamiento especular del edificio. Fijémonos en la doble página que presenta el palacio del Gobernador en la CEuvre complète 1946-52. Bajo el croquis que concluye la serie se indica que estamos ante el diseño definitivo del palacio del Gobernador, con fecha 12 de abril de 1952 (figura 12), si bien la vista muestra el edificio como una simple silueta. Pensemos que el primer proyecto completo del palacio es de enero de 1954. El croquis, por el contrario, se recrea en los jardines que lo preceden, dispuestos en varios niveles como resultado del uso combinado de la topografía y los reflejos. Debemos entender entonces que edificio y jardines constituyen el palacio del Gobernador. Incluso cabría precisar que el podio sobre el que se levanta propiamente la casa del Gobernador, y ésta última son elementos de naturaleza distinta entre sí, como lo son el recorte redondeado de terreno y el árbol que Le Corbusier dibuja sobre aquél. Todos estos elementos reunidos forman el palacio -entendido como suma de edificio y jardín- pero, con esta división en altura, el podio pasa a formar parte de la topografía de los jardines.

El podio y los jardines deprimidos, forman una unidad en equilibrio que se puede leer como conjunto de relieves y contrarrelieves; como excavación y relleno mientras que, sin la ayuda del podio, sólo se puede hablar de vaciado del terreno. Esta hipótesis, en clave de simetría plástica, ofrece una lectura plausible del proceso que seguirá, tiempo después, el monumento de la Mano Abierta, en el lado opuesto del eje llano - montaña que divide el Capitolio. Aquí, excavación y relleno se invertirán: el foso de la Mano Abierta respecto al podio del palacio y el parterre elevado que la precede -con origen en el croquis FLC W1-3-27, de 1954- respecto al vaciado de los jardines. Es como disponer, uno junto a otro, un molde y su vaciado, de modo análogo al relieve que Le Corbusier ejecutó en la playa de Long Island el verano de 1951.

En este 'diseño definitivo', el edificio se desdobla parcialmente en el estanque inmediato; a cota de la explanada. Más exactamente, Le Corbusier duplica el brisesoleil que constituye el podio del edificio. Los estanques restantes, deprimidos respecto al nivel de la explanada, no duplican el edificio, sino únicamente los muros de 
contención dispuestos tras de sí, de altura comparable a la del podio. Los reflejos actúan sobre estos muros como lo hacen sobre el brise-soleil del palacio.

El resultado es un conjunto de muros desdoblados frontalmente al observador que prolongan -como un eco- la presencia del edificio hasta el punto de vista, favoreciendo así la aparición del palacio a la que se refería Le Corbusier. Los elementos de la composición no son los estanques, sino los reflejos; no la materia, sino la pareja indisoluble que forma con su duplicado invertido, en suspensión ante la transparencia del cielo real y reflejado y en contraste con las presencias opacas de otros objetos como la colina con árbol, el perfil de guitarra y el obelisco.

Los muros desdoblados actúan, ahora sí, acercando visualmente el edificio al repetir, amplificada, una solución tipo que proporciona al edificio y a los jardines unidad plástica; reforzada por la equivalencia que Le Corbusier establece entre el podio del edificio y la plataforma central y por la continuidad óptica entre la envolvente escalonada del edificio y el contorno aparente de los jardines. Se hace realidad con ello la creación del elemento vertical que Le Corbusier requería en sus notas iniciales, sólo que el elemento ha resultado no ser tan vertical. El dibujo prolonga la línea oblicua de la silueta del edificio en forma de líneas de fuga de los jardines, ignorando el pliegue de $90^{\circ}$ entre una y otras; es el mariage des contours de una superficie bidimensional.

Este efecto de compresión pictórica del espacio no es fácil de trasladar a la arquitectura literalmente, puesto que ésta trabaja con tres dimensiones reales y no sugeridas, pero la visión frontal de los jardines parece dar resultados. Para asegurar la ambivalencia de los elementos en perspectiva que se pretende comprimir en profundidad, Le Corbusier desmonta a conciencia los recursos de la perspectiva clásica: las líneas de fuga de los jardines, que convergen en el edificio quedan interrumpidas por los cambios de alineación sucesivos del camino; aparecen las falsas fugas de rampas y escaleras; y los contornos laterales se desdibujan con la aparición de formas orgánicas y con el escalonado de la silueta del edificio; todo inscrito, recordémoslo, dentro un mariage del contorno aparente de los jardines y el edificio.

Sin embargo, para hacer efectivo este mariage, debe asegurar la primacía de un punto de vista. La disposición de la rampa del monumento a los Mártires, a las puertas de los jardines, juega este papel de atalaya para contemplar "le hors d'œuvre en marqueterie", combinando la elevación del observador con la depresión de los jardines. Le Corbusier materializa, de este modo, la intuición inicial de "rendre visible [le palais] par des positions surélevés de face à celui" a pesar de que, justamente, la existencia de un punto de vista privilegiado pueda debilitar la relación con el resto del recinto.

\section{LA ARQUITECTURA DEL SUELO}

De vuelta a París, Le Corbusier hace una breve escala en Egipto, entre el 19 y 23 abril, para conocer las pirámides de Gizeh y el museo egipcio de El Cairo. Esta decisión -postergada indefinidamente al final de su viaje a Oriente ${ }^{45}$ - se produce durante el proceso de gestación del Capitolio. Podemos interpretar la visita en continuidad con las observaciones que ha estado realizando "sur place" en la India.

Los croquis realizados en Gizeh no comportan cambios aparentes en la composición del Capitolio, si bien en los temas que se apuntan resuenan las distancias relativas entre elementos, los relieves producidos por excavaciones y emergencias, los efectos de ocultaciones y revelaciones parciales o las incisiones producidas sobre el terreno, que se han ido perfilando durante las semanas anteriores. Esta resonancia se mueve en el terreno de las confirmaciones, indicativas de los términos con los que compara el "parc du Capitol": el vasto gesto de las pirámides, capaz de abrazar con su presencia el espacio a su entorno. "Il fallait occuper la plaine. L'événement géométrique était, à vrai dire, une sculpture intellectualisée"46.

Y Le Corbusier ocupa la llanura, antes vacía de contenidos y de significados. No lo hace disponiendo objetos sobre una superficie; sino disolviendo objetos y superficie en una única categoría, gracias al uso de un solo material -el hormigón armado en bruto- y mediante la activación

45. "Je n'aborderai point une nouvelle culture. Le geste des Pyramides est vaste et je suis trop las". Le Corbusier (Jeanneret, Charles-Édouard): Le voyage d'Orient. París: Forces Vives, 1965. Reedición Marsella: Parenthèses, 1987. p. 168.

46. Le Corbusier: Modulor 2. Boulogne: L'Architecture d'Aujourd'hui, 1955. p. 226. 
de la topografía y la relación sistémica con el agua estancada, que constituyen el propósito de este tercer viaje. El Capitolio es, desde este punto de vista, una máquina para suscitar resonancias entre elementos. Mediante la manipulación del suelo y de sus alteraciones, Le Corbusier construye un 'objeto extenso' capaz de administrar los vínculos perceptibles entre los edificios.

Para perfilar esta relación entre las partes, dispone además de la colaboración inesperada de un conjunto de actores que hace aparición progresivamente a partir de este tercer viaje. Jane Drew le sugiere el uso de "signes d'urbanisme, de sociologie et de plastique", en una conversación mantenida la noche del 8 de abri ${ }^{47}$ y, como respuesta, Le Corbusier emprende la construcción simbólica de un entramado de elementos, a los que otorga la capacidad de puntuar la explanada del Capitolio: a la Mano Abierta y el monumento a los Mártires - una rampa ceremonial- cabe añadir ahora las trayectorias solares, la jornada de 24 horas, el Modulor o, más adelante, la torre de las Sombras. Con ellos, las distancias se alteran y el plano medio adquiere un mayor peso, interponiéndose entre los ojos del observador y los palacios que el parque del Capitolio pone en relación.

Esa arquitectura del suelo -tal como la define Josefina González Cubero ${ }^{48}$ - actúa promoviendo los edificios, las colinas artificiales y algunos de los signos utilizados a la categoría de emergencias del plano horizontal, contrapuestos a las incisiones reales o figuradas -causadas por reflejos en los estanques- sobre ese mismo terreno artificial, que se complementan mutuamente, en un estado de equilibrio que haría insuficiente cualquier análisis de las partes por separado. Y como sistema en equilibrio, las modificaciones introducidas durante la larga gestación del recinto, acabarán por encontrar nuevas situaciones de estabilidad.

Para la versión definitiva del Capitolio, será necesario esperar todavía cuatro años, hasta la elaboración del plano CHAND LC 5340, de 8 de febrero de 1956, que servirá de base al desarrollo de un proyecto de ejecución, construido a medias. En el camino que queda por recorrer, el palacio de la Asamblea transforma substancialmente el pórtico que lo precede y se reduce la dimensión del palacio del Gobernador; las colinas artificiales colonizan sistemáticamente el llano y, de ellas, una elevación geométrica ocupa una posición central en el recinto, discriminando las ocultaciones y revelaciones de los elementos y edificios del Capitolio; se simplifica el contorno de los jardines del Gobernador; se invierte la posición de la fosa de la Mano Abierta respecto al límite de la plataforma y se eleva un parterre entre esta fosa y el eje transversal del recinto, como réplica a la geometría de dichos jardines; la torre de las Sombras articula los signos solares dispuestos a su alrededor, como si se tratase de un particular observatorio astronómico; la rampa del monumento a los Mártires se desliza hasta casi ocluir la entrada a los jardines del Gobernador. Paralelamente, como si se mantuviese al margen de estos cambios, el agua de los estanques se limita a reflejarlos, dando así testimonio paciente de los mismos.

De hecho, más que cambios en sentido estricto, deberíamos hablar de variaciones sobre un tema inicial. Como en una composición musical, el material arquitectónico se repite alterando alguna de sus propiedades, sobre un patrón común que lo hace reconocible. La intensificación de la presencia de colinas, las inversiones en el relieve del ámbito de la Mano Abierta o el aspecto que adopta el pórtico de la Asamblea pueden ser entendidos -como la mayoría de las modificaciones- en relación al tema que les ha dado entrada en el sistema. La propuesta de 1952, concentrada en el plano CHAND LC 4445, conserva intactas las claves para interpretar esas futuras variaciones, que no hacen más que ahondar en Ios temas que Le Corbusier desarrolla durante este tercer viaje, pero eso ya merecería un capítulo aparte.

47. "Corbu, vous devez, en plein Capitol, manifester 'vos signes' d'urbanisme, de sociologie et de plastique par une création de sculptures diverses en pierre, ciment ou bronze [...] Cette tâche Jane est la plus belle qu'on m'ait jamais proposé [...] des signes, est ce qui est au plus profond de moin. Nota de Le Corbusier reseñando la conversación, FLC W1.8.144.

48. González Cubero, Josefina: "La arquitectura del suelo: las casas Jaoul en Neuilly-sur-Seine”. Massilia 2003. Anuario de estudios lecorbusierianos. BarceIona: Fundación Caja de Arquitectos, 2003. pp. 162-177. 


\section{Bibliografía}

Carnets. Le Corbusier, 1887-1965, Milán: Electa, 1981-1982. 4 volúmenes. Prefacio de André Wogenscky, introducción de Maurice Besset. Chandigarh, la ville indienne de Le Corbusier. París: Somogy - Boulogne-Billancourt: Musée des Années 30, 2002.

Le Corbusier Plans. Y. Shimoda (Prod.); Echelle-1 (Ed.). Paris [etc.]: Codex Images, 2005-. Recurso electrónico constituido por 16 discos ópticos (CVDROM). Volúmenes 10 y 11.

The Le Corbusier Archive. H. Allen Brooks (Ed.). Nueva York [etc.]: Garland - París: Fondation Le Corbusier, 1982-1984. Volúmenes 22 a 25.

Álvarez, Darío: “Ici pas d'autos = un parc'. El Capitolio de Chandigarh, un jardín de la memoria”. Massilia 2004bis. Le Corbusier y el paisaje. Sant Cugat del Vallès (España): Associació d'idees, 2004. pp. 100-125.

Capitel, Antón: “Topografía y suelo en la tierra de Chandigarh”, Pasajes de arquitectura y crítica. № 9. Septiembre 1999. Madrid: América Ibérica. ISSN 1575-1937. pp. 34-37.

Cohen, Jean-Louis; Benton, Tim: Le Corbusier Le Grand, Londres: Phaidon Press, 2008.

Fuertes, Pere: Le Corbusier desde el palacio del Gobernador. Un análisis de la arquitectura del Capitolio de Chandigarh [en línea]. Barcelona: TDX Universitat Politècnica de Catalunya, 2007. Disponible en World Wide Web: http://www.tdx.cat/TDX-0425107-125329.

González Cubero, Josefina: "La arquitectura del suelo: las casas Jaoul en Neuilly-sur-Seine”. Massilia 2003. Anuario de estudios lecorbusierianos. Barcelona: Fundación Caja de Arquitectos, 2003. pp. 162-177.

Le Corbusier: La ville radieuse. Boulogne. L'Architecture d'Aujourd'hui, 1935.

Le Corbusier (Jeanneret, Charles-Édouard): Le voyage d'Orient. París: Forces Vives, 1965.

Le Corbusier: Modulor 2. Boulogne: L’Architecture d'Aujourd'hui, 1955.

Le Corbusier; Jeanneret, Pierre: CEuvre complète 1910-29. W. Boesiger(Ed.), 0.Stonorov (Ed.).Zurich:Girsberger, 1929. ReediciónZurich:Artemis, 1964.

Le Corbusier: CEuvre complète 1946-52. W. Boesiger (Ed.). Zurich: Girsberger, 1953. Reedición Zurich: Artemis, 1957.

Le Corbusier: CEuvre complète 1952-57. W. Boesiger (Ed.). Zurich: Girsberger, 1957.

Le Corbusier: Précisions sur un état présent de l'architecture et de l'urbanisme. París: Crès, 1930.

Le Corbusier: Vers une architecture. París: Crès, 1923. Reedición París: Arthaud, 1977.

Lucan, Jacques (Ed.): Le Corbusier, une encyclopédie. París: Centre Georges Pompidou, 1987.

Millet, Marion: Architecture: de la restitution face à l'inconstruit. École d'Architecture de Paris-Belleville, 2003. DEA no publicado.

Millet, Marion: Tentative de Restitution Historique d'un projet urbain de Le Corbusier : Le Capitole de Chandigarh. Director: Remi Papillault. École d'architecture de Paris-Défense, 2000. TPFE no publicada.

Papillault, Rémi: "Chandigarh de Le Corbusier ou le goût de l'Inde”. Chandigarh: La ville indienne de Le Corbusier. Le Capitole, une oeuvre inachevée. París: Musée des Anées 30 Boulogne-Billancourt - Somogy, 2002.

Quetglas, Josep: “Viajes alrededor de mi alcoba”. Artículos de ocasión. Barcelona: Gustavo Gili, 2004.

Pere Fuertes Pérez (Terrassa, Barcelona, 1966), arquitecto (1993) y doctor arquitecto (2006) por la Universitat Politècnica de Catalunya. Profesor lector de Proyectos Arquitectónicos en la Escuela Técnica Superior de Arquitectura del Vallès (UPC). Miembro del grupo de investigación HABITAR. Ha sido profesor del departamento de Historia en la Escuela Superior de Diseño BAU, UVic (20002003). Ha publicado el libro Casa Collage y artículos en Massilia 2008 y Arquitectura Ibérica $n^{0} 32$. Desarrolla, con el grupo de investigación, el ciclo de exposiciones Rehabitar en el Ministerio de Vivienda. 


\section{Autor imagen y fuente bibliográfica de procedencia}

Información facilitada por los autores de los artículos: página 18, 1 (FINE LICHT, K.: The Rotunda in Rome. A study oh Hadrian's Pantheon. Koblnhavn, Jutland Archeological Society, 1966, p. 238); página 19, 2 (SCHRAUDOLPH, E: Der Ruhm des Pantheon. Berlin: Estaatliche Museum zu Berlin, 1992, p. 37), 3 ( http://www.info.roma.it/foto/roma_sparita/ grandi/221.jpg, consulta junio 2010); página 20, 4 y 5 (Francisco J. Montero Fernández); pagina 22, 6 (Francisco J. Montero Fernández); página 24, 7 (dibujo Francisco J. Montero Fernández, 2010), 8 (BOESIGER W.: Le Corbusier. Obra completa 1957-1965. volumen 7. Zürich,: Girsberger, 1965-1985, pp.182); página 25, 9 (dibujo Francisco J. Montero Fernández, 2010); página 26, 10 (dibujo Francisco J. Montero Fernández, 2010); página 27, 11 y 12 (dibujo Francisco J. Montero Fernández, 2010); página 29, 13 y 14 (Francisco J. Montero Fernández); página 31, 15, a 17 (Francisco J. Montero Fernández); página 35, 1 (Nárödni Galerie, Praga); página 38, 2 (SEKLER, Eduard: Josef Hoffmann: the Architectural Work. New Jersey: Princeton, 1985, p. 59), 3 (Nárödni Galerie, Praga), 4 (Lyon: L'Aventurine, 2006, p.16); página 39, 5 (Lyon: L'Aventurine, 2006, p.20 y p. 104); página 40, 6 (publicado por Meda Mladek en Frank Kupka. Colonia: Galerie Gmurzynska, 1981, pp. 59 y 53); página 41, 7 (publicados por Meda Mladek en Frank Kupka. Colonia: Galerie Gmurzynska, 1981, p. 43); página 42, 8 (publicado en VV.AA.: František Kupka, Barcelona: Fundació Joan Miró, 2009, p. 66); página 43, 9 (publicado en VV.AA.: František Kupka, Barcelona: Fundación Joan Miró, 2009, p. 44); página 44, 10 (Fotografía de Dos\&Bertie Winkel); página 45, 11 (publicado en WILLIAM, David: Naval Camouflage 1914-1945. Annapolis: Naval Institute Press, 2001, p. 134); página 53, 1 (CFLC 5845); página 56, 2 (CFLC 2029); página 57, 3 (CFLC. L4(19) 95); página 59, 4 (CFLC 2856); página 64, 1 (VARNEDOE, Kirk (ed.): Northern light. Realism and symbolism in scandinavian painting. NY: Brooklyn Museum, 1983); página 65, 2 (Archivo Larsson del Nationalmuseum, Estocolmo); página 66, 3 (Arriba: CALDENBY, Claes; Joran LINDVALL y Wilfried WANG (eds.): Sweden. 20th-century architecture. NY: Prestel, 1998. Abajo: Archivo fotográfico de SVAASCP); página 68, 4 (Arriba: LEJEUNE, Jean-Françoise y Michelangelo SABATINO (eds.): Modern architecture and the vernacular dialogues and contested identities. Nueva York: Routledge, 2010. Abajo: BLUNDELL-JONES, Peter: Asplund. NY: Phaidon, 2006); página 70, 5 (dibujos, archivo SVAASCP, 2010); página 72, 6 (Izquierda.: BRUMMER, Hans H.: Prins Eugen - Minnet av ett landskap. Estocolmo: PE Waldemarsudde, 1998. Derecha: KAWASHIMA, Yoichi (ed.): E.G. Asplund. Tokio: TOTO, 2005); página 73, 7 (dibujos archivo SVAASCP, 2010); página 74, 8 (Izquierda: Archivo Asplund del Arkitekturmuseet, Estocolmo. Centro: LINDWALL, Bo: Carl Larsson. Aquarelles. París: Bib. de l'image, 1994. Derecha: CRUICKSHANK, Dan (ed.): Erik Gunnar Asplund. Londres: AJ, 1988); página 76, 9 (Izquierda: Archivo Asplund del Arkitekturmuseet, Estocolmo. Arriba: VARNEDOE, Kirk (ed.): Northern light. Realism and symbolism in scandinavian painting. NY: Brooklyn Museum, 1983. Centro: Archivo Asplund del Arkitekturmuseet, Estocolmo. Abajo: Archivo Asplund del Arkitekturmuseet, Estocolmo); página 77, 10 (Archivo Asplund del Arkitekturmuseet, Estocolmo); página 84, 1 (Hugo Häring Archiv, Stiftung Archiv der Akademie der Künste, Berlin, ᄂ 15/4); página 85, 2 y 3 (dibujos Rafael Schlatter Martínez, 2010); página 86, 4 (dibujos Rafael Schlatter Martínez, 2010); página 87, 5 (Hugo Häring Archiv, Stiftung Archiv der Akademie der Künste, Berlin, ᄂ 18/7), 6 (dibujos Rafael Schlatter Martínez, 2010); página 88, 7 (BLUNDELL JONES, Peter: Hugo Häring, the Organic versus the Geometric. Stuttgart \& London: Axel Menges, 1999); 8 (Hugo Häring Archiv, Stiftung Archiv der Akademie der Künste, Berlin); página 89, 9 (KAHN, Fritz: Anatomie, Biologie, Physiologie und Entwick-lungs-geschichte des Menschen. Vol. 2, Stuttgart, 1926); página 92, 10 (Hugo Häring Archiv, Stiftung Archiv der Akademie der Künste, Berlin, ᄂ 96/1); página 97, 1 (fotografía Anna Armstrong); página 98, 2 (fotografía Anna Armstrong); página 99, 3 (Archivo Sir Owen Williams and Partners); página 100, 4 y 5 (fotografía y dibujo Teresa Rovira Llobera); página 101, 5 (Archivo Sir Owen Williams and Partners); página 102, 6 (fotografía Archivo Sir Owen Williams and Partners. Dibujo Teresa Rovira Llobera); página 103, 7 (fotografía: Raphl Morris. Dibujo Teresa Rovira Llobera); página 105, 8 (fotografía Joseph McGarraghy); página 106, 9 (Archivo Sir Owen Williams and Partners. Fotografía Duncan Campbell); página 107, 10 (Archivo Sir Owen Williams and Partners); páginas 121 a 132, 1 a 12 (Fondation Le Corbusier, FLC - ADAG P. 11, rue Berryer, 75008 París); página 137, 1 (Los Angeles County Museum of Art); página 139, 2 (C 1924 Mezhrabprom-Rus, ( 2004 RUSCIC0), 3 (@ 1929 Universum Film AG); página 140, 4 (Metropolis @ 1926 Universum Film AG); página 142, 5 (@ 1956 Turner Entertainment Co.); página 143, 6 (Star Wars 1977 Lucasfilm Ltd., Alien @ 1979 Twentieth Century Fox Film Corporation, Stargate Atlantis @ 2004 MGM Global Holdings Ltd.); página 144, 7 (๔ 1968 Turner Entertainment Co.); página 146, 8 (THX 1138 @ 1970 Warner Bros. Entertainment Inc., Blade Runner @ 1982 The Blade Runner Partnership), 9 (Solaris ( 1972 Mosfilm); página 147, 10 (๔ 1968 Turner Entertainment Co); página 148, 11 (C 1980 Lucasfilm, Ltd); página 151, 12 ("Alien's cockpit» @ 1978 HR Giger, obra n. 377, acrílico sobre papel, 70x100 cm. Alien ( 1979 Twentieth Century Fox Film Corporation.); página 152, 13 (Dune ㄷ 1984 Dino de Laurentiis Corporation. Brazil (C) 1985 Universal Studios); página 153, 14 (Solaris y Stalker @ 1972 y 1979 Mosfilm) 